\title{
PRODUÇÃO DE TOMATEIRO, HÍBRIDO MOMOTARO, EM FUNÇÃO DO ESTÁDIO DAS MUDAS E DA ENXERTIA
}

\author{
Production of tomato, momotaro hibrid according to \\ seedling stage and grafting
}

\author{
Rumy Goto ${ }^{1}$, Luchele Furlan Sirtori², João Domingos Rodrigues ${ }^{3}$, Mario César Lopes ${ }^{4}$
}

\begin{abstract}
RESUMO
O trabalho foi conduzido em ambiente protegido, UNESP- Fazenda Experimental São Manuel da Faculdade de Ciências Agronômicas - Botucatu no município de São Manuel-SP no solo classificado como Latossolo Vermelho Amarelo fase arenosa. Determinou-se o estádio de desenvolvimento da muda para o transplante, com cinco a seis folhas definitivas, em estádio de plena floração e em início da frutificação. O tomateiro (Lycopersicon esculentum Mill), híbrido Momotaro T-93, foi cultivado sobre dois porta-enxertos, os híbridos Anchor T e Kaguemusha e em pé franco. Avaliou-se área foliar, comprimento e massa seca das mudas no momento do transplante; número de folhas total/planta; massa fresca e seca das folhas abaixo do terceiro cacho floral e classificação dos frutos em diâmetro e produção total até o $8^{\circ}$ cacho. Conclui-se que o estádio de desenvolvimento de mudas de pé franco, transplantadas com 5 a 6 folhas definitivas, é o que apresenta as maiores médias para produção e diâmetro médio de frutos. Para mudas enxertadas, o estádio de cinco a seis folhas definitivas até plena floração, não houve diferença na produtividade e qualidade final, sendo os melhores desempenhos obtidos pelo porta-enxerto Anchor T.
\end{abstract}

Termos para indexação: Lycopersicon esculentum, cultivo protegido, estádio de transplante.

\section{ABSTRACT}

This work was carried out in a protected environment at Sa Paulo State University (UNESP) São Manuel Experimental Farm, College of Agronomical Sciences, São Manuel Municipality, São Paulo State, Brazil. The local soil was red-yellow sandy-phase latosol. The following development stages for transplanting were evaluated: seedlings presenting 5 to 6 definitive leaves, in full flowering and beginning of fruiting. Momotaro T-93 hybrid tomato (Lycopersicon esculentum Mill.) was grown on two rootstocks, the hybrids Anchor T and Kaguemusha, and in non-grafted ones. Evaluations included leaf area, seedling length, seedling dry matter at the moment of the transplant, total number of leaves per plant, fresh and dry matter of leaves below the third inflorescence, fruit classification according to diameter, and total fruit production until the eighth bunch. Non-grafted plants transplanted when they presented 5 to 6 definitive leaves had the highest mean fruit production and diameter. As regards grafted plants, no difference was detected concerning productivity and final quality when seedlings were in the stages from 5 to 6 definitive leaves until full flowering, and the rootstock Anchor T presented the best development.

Index terms: Lycopersicon esculentum, protected cultivation, transplanting stages.

(Recebido em 14 de janeiro de 2009 e aprovado em 30 de outubro de 2009)

\section{INTRODUÇÃo}

O cultivo do tomateiro (Lycopersicon esculentum Mill.) é amplamente praticado no Brasil. A área de cultivo é de 54.931 hectares com produção total de 3.154.982 toneladas, sendo uma das hortaliças de maior destaque pelo consumo de frutos (AGRIANUAL, 2007).

O cultivo do tomateiro apresenta vários problemas, principalmente no que se refere a doenças. Há demanda de médio a longo prazo na obtenção de materiais resistentes e com características agronômicas exigidas pelo mercado, ainda que o híbrido resistente nem sempre permaneça eficiente por muito tempo, principalmente quando essa resistência é monogênica para cada raça fisiológica de fungo.

Em ambientes protegidos, os problemas com fungos presentes no solo tendem a agravar-se em razão do cultivo intensivo. Como o mercado exige determinados padrões e não dispondo comercialmente de materiais resistentes a determinadas doenças, a utilização de porta-enxerto resistente é uma alternativa para controlar o problema em curto prazo.

Atualmente, em outros países e, principalmente, no Japão, existem muitos trabalhos a respeito de enxertia relacionados ao controle de doenças causadas por patógenos do solo. Nesses são enfocados, principalmente, a compatibilidade de porta-enxerto com o enxerto, absorção

\footnotetext{
'Universidade Estadual Paulista “Julho de Mesquita filho"/UNESP - Departamento de Produção vegetal - Botucatu - SP - rumy@fca.unesp.br 2Universidade Estadual Paulista "Julho de Mesquita filho"/UNESP - Departamento de Produção Vegetal/Horticultura - Botucatu - SP

3Universidade Estadual Paulista “Julho de Mesquita filho"/UNESP - Departamento de Botânica - Botucatu - SP

${ }^{4}$ Centro de Ciências Agrárias - Marechal Cândido Rondon - PR (in memoriam)
} 
de nutrientes, crescimento vegetativo, qualidade de frutos, produção em função da enxertia e poucos trabalhos em relação à nutrição e translocação de compostos químicos e fotossintatos na planta enxertada. No Brasil, pode-se dizer que esses trabalhos são praticamente inexistentes, principalmente por essa necessidade de cultivos em ambiente protegido ter tomado impulso nos últimos 20 anos.

No que se refere ao estádio de desenvolvimento para efeito de transplante, um dos principais problemas que se tem no Brasil, na cultura do tomateiro, é a ocorrência de viroses, principalmente nos 60 dias após o transplante. Uma das formas de se preservar as plantas desse problema é retardar o processo de transplante, mantendo as mudas por mais tempo em ambientes "controlados" (viveiros) em condições ideais, levando-as ao campo com menor risco. Assim, garantem-se plantas mais sadias e com maior capacidade de produção com qualidade, pelo fato do tomate do tipo Momotaro não tolerar transplante muito precoce.

Vários tipos de enxertia para tomateiros são realizados no Japão, sendo que os mais utilizados são a encostia e a enxertia por fenda simples. O método denominado encostia apresenta sucesso quando as plantas enxertadas são submetidas a condições de temperatura amena e alta umidade. A desvantagem é que a união entre o porta-enxerto e o enxerto tende a ser mais frágil. O método mais indicado é a enxertia tipo fenda simples, que consiste em utilizar porta-enxertos no estádio de 5 a 6 folhas verdadeiras, sendo o ponto de enxertia realizado na terceira folha verdadeira (Yamakawa, 1982).

$\mathrm{Na}$ enxertia de tomateiros com o porta-enxerto KNVF, ocorreu aumento de 30 a $50 \%$ na produção de tomate enxertado quando comparada com plantas não enxertadas da mesma cultivar utilizada como enxerto. As plantas enxertadas apresentam também maior massa fresca da parte aérea e do sistema radicular, bem como maior quantidade de macronutrientes nas folhas (Piróg, 1986).

Estudos mais aprofundados podem ser observados no desempenho das plantas enxertadas de tomateiro, tais como; crescimento das mudas, eficiência fotossintética, translocação de fotossintatos e atividade do sistema radicular na presença ou na ausência de folhas no portaenxerto. Esse desempenho foi verificado na cultivar Fukuju N.2, enxertada pelo método tipo fenda em porta-enxerto da cultivar KNVF (Yoshioka et al. (1981).

Com base nessas informações, muitos problemas podem ser atribuídos à enxertia, principalmente no que se refere à fisiologia da planta enxertada.

Conduziu-se este estudo, com o objetivo de avaliar diferentes estádios de desenvolvimento das mudas de tomateiro, híbrido Momotaro, tanto de pé franco como enxertado sobre dois porta-enxertos, estudando o desempenho em relação ao desenvolvimento das mudas e produção final.

\section{MATERIAL E MÉTODOS}

O ensaio foi desenvolvido na Fazenda Experimental São Manuel, da Faculdade de Ciências Agronômicas/ UNESP, Campus de Botucatu, com longitude $48^{\circ} 34^{\prime} \mathrm{W}$ GR; latitude $22^{\circ} 44^{\prime} \mathrm{S}$ e altitude de $750 \mathrm{~m}$, localizada no município de São Manuel - SP.

O clima caracteriza-se como subtropical úmido, com estiagens no inverno, média anual de temperatura em torno de $21{ }^{\circ} \mathrm{C}$ e precipitação média anual de $1534 \mathrm{~mm}$. O solo do local foi classificado como Latossolo Vermelho Amarelo fase arenosa.

O delineamento experimental foi de blocos ao acaso, em esquema fatorial de $3 \times 3$, num total de nove tratamentos e quatro repetições, onde os fatores empregados foram três estádios de desenvolvimento das mudas a serem transplantadas $\left(1^{\circ}\right.$ com cinco a seis folhas definitivas; $2^{\circ}$ plena floração e $3^{\circ}$ início de frutificação) e três tipos de mudas (dois tipos de porta-enxertos e plantas obtidas de pé franco), sendo utilizada como copa e pé franco o 'Momotaro T-93' assim descritos: Porta-enxerto 'Kaguemusha' transplantado no início da frutificação (T1); Porta-enxerto 'Anchor T' transplantado no início da frutificação (T2); pé franco 'Momotaro T-93' transplantado no início da frutificação (T3); Porta-enxerto 'Kaguemusha' transplantado com plena floração (T4); Porta-enxerto 'Anchor T' transplantado com plena floração (T5); pé franco 'Momotaro T-93' transplantado com plena floração (T6); Porta-enxerto 'Kaguemusha' transplantado com cinco a seis folhas definitivas (T7); Portaenxerto 'Anchor T' transplantado com cinco a seis folhas definitivas (T8); pé franco 'Momotaro T-93' transplantado com cinco a seis folhas definitivas (T9).

Definiu-se os estádios de plena floração como a abertura total das flores do primeiro racemo e como início de frutificação os frutos do primeiro cacho com diâmetros de 2 a $3 \mathrm{~cm}$.

Foram instaladas cinco linhas espaçadas de $1,2 \mathrm{x}$ $0,6 \mathrm{~m}$ entre plantas. Cada parcela $\left(7,2 \mathrm{~m}^{2}\right)$ constou de 10 plantas, sendo utilizadas cinco para efeito das avaliações.

As semeaduras foram realizadas em bandejas de poliestireno expandido com 128 células, utilizando-se substrato comercial Solomax ${ }^{\circledR}$, onde colocou-se uma semente em cada célula, de forma escalonada a representar os estádios de desenvolvimento determinados para o experimento. Suplementaram-se as mudas com fertilizante líquido (10-05-05 + micronutrientes) na dosagem de $1 \mathrm{~mL}$ $\mathrm{L}^{-1}$ de água. 
A primeira fase da enxertia para as mudas a serem transplantadas com início de frutificação, foi realizada no dia 27/11/1997 em viveiro coberto com plástico e cortinas laterais de sombrite.

O processo utilizado foi enxertia de fenda simples, mantendo-se de uma a três folhas no porta enxerto e três a quatro folhas no enxerto e em seguida fixada pelo grampo de enxertia recomendado para o tomateiro.

As mudas após a enxertia foram transplantadas para vasos com capacidade de $0,8 \mathrm{~L}$ preenchidos com o substrato Solomax ${ }^{\circledR}$ classificado como condicionador de solo, apresentando as seguintes características: $83 \%$ de matéria orgânica; $1 \%$ de nitrogênio; $1 \%$ de magnésio e 0,4\% de cálcio; $\mathrm{pH}$ de 7,2; CTC de 182,0 meq $100 \mathrm{~m}^{-1}$; CRA de 225\%; MEA de $585 \mathrm{~kg} \mathrm{~m}^{-3}$ e CE de $0,58 \mathrm{mS} \mathrm{cm}^{-1}$.

Após o transplante para os vasos, as mudas foram colocadas sob câmara úmida de $50 \mathrm{~cm}$ de altura e cobertas por plástico preto durante três dias e mais dois dias por plástico transparente e, quando necessário, por tela de coloração prateada, mantendo-se a umidade relativa sempre próxima a $100 \%$ e fazendo a troca de ar, ou seja, abertura do plástico de quatro a cinco vezes por dia, em seguida deixadas nas condições ambientais conferidas pelo viveiro.

Durante a fase de pós-pega da enxertia, foi realizada no dia 10/12/1997 uma suplementação nutricional nas mudas da primeira fase com Plantafol ${ }^{\circledR}$ fórmula 15-15-45 + micronutrientes na dosagem de $2 \mathrm{~g} \mathrm{~L}^{-1}$ na forma de rega, essa suplementação foi utilizada para todas as mudas das outras fases. Nesse mesmo período, as mudas de pé-franco e enxertadas da primeira fase foram desbrotadas e tutoradas com bambu colocado dentro do vaso e fixado por alceador. Após a desbrota foi feita aplicação com oxicloreto de cobre $1 \mathrm{~g} \mathrm{~L}^{-1}$ para controlar patógenos e porque o cobre apresenta efeito cicatrizante.

A segunda fase de enxertia para mudas a serem transplantadas com plena floração foi realizada no dia 15/ 12/1997 com os mesmos procedimentos descritos anteriormente. A enxertia para a terceira fase para mudas a serem transplantadas com cinco folhas definitivas foi realizada em 06/01/1998, tendo a instalação do experimento ocorrido no dia 18/01/1998, na área definitiva em ambiente protegido.

No viveiro, onde as mudas foram enxertadas e permaneceram após a enxertia, foi instalado sistema de irrigação por nebulização com duas linhas espaçadas de 3,0 m, onde foram colocados quatro bicos nebulizadores em cada ponto distanciados de 3,0 m, com o objetivo de cobrir toda a área da estufa. O controle da umidade na fase pós- enxertia foi feito com nebulizador controlado por folha mágica.
O preparo do solo constituiu-se de subsolagem, uma aração e duas gradagens. Os resultados da analise química do solo para a amostra $0-30 \mathrm{~cm}$ e $30-60 \mathrm{~cm}$, respectivamente foram: $\mathrm{pH}\left(\mathrm{Ca} \mathrm{Cl}_{2} 0,01 \mathrm{~mol} \mathrm{~L}^{-1}\right): 5,1$ e 4,5; $\mathrm{P}\left(\mathrm{mg} \mathrm{dm}^{-3}\right): 9$ e $2 ; \mathrm{K}\left(\mathrm{mmol}_{\mathrm{c}} \mathrm{dm}^{-3}\right): 0,9$ e 1,$3 ; \mathrm{Ca}\left(\mathrm{mmol}_{\mathrm{c}} \mathrm{dm}^{-3}\right)$ : 9 e $8 ; \mathrm{Mg}\left(\mathrm{mmol}_{\mathrm{c}} \mathrm{dm}^{-3}\right): 5$ e $3 ; \mathrm{H}+\mathrm{Al}\left(\mathrm{mmol} . \mathrm{dm}^{-3}\right): 14$ e 16 ; CTC $\left(\mathrm{mmol}_{\mathrm{c}} \mathrm{dm}^{-3}\right): 29$ e 29; saturação por bases (\%): $52 \mathrm{e}$ 43; matéria orgânica $\left(\mathrm{mg} \mathrm{dm}^{-3}\right)$ : 9 e 2 .

A calagem foi realizada aplicando o calcário com P.R.N.T. estimado em $96 \%$. Espalhou-se manualmente, a lanço, as quantidades necessárias e incorporou-se com arado juntamente com composto orgânico, na proporção de 4,0 $\mathrm{L} \mathrm{m}^{-2}$.

Foi realizada a adubação mineral com $150 \mathrm{~g} \mathrm{~m}^{-2} \mathrm{de}$ termofosfato (Yoorin BZ) $+150 \mathrm{~g} \mathrm{~m}^{-2}$ de superfosfato simples e as demais aplicações foram feitas via fertirrigação, uma vez por semana, utilizando $50 \%$ do tempo de irrigação para a aplicação dos fertilizantes, colocados no sistema de irrigação por bomba injetora (modelo DP 30-2 DOSMATIC).

Foram utilizados o fertilizante nitrato de cálcio hidrossolúvel (14,5\% de $\mathrm{N}$ nítrico, 1,0\% de $\mathrm{N}$ amoniacal e $19 \%$ de Ca) e duas fórmulas para fertirrigação da Valagro ${ }^{\circledR}$, a 5-15-45 + 0,04 B e a 15-5-30 + $2 \mathrm{Mg}$ com micronutrientes. Além desses adubos, utilizou-se também aplicação de bórax $(11,5 \%$ B) e três aplicações foliares de sulfato de zinco a $0,3 \%$.

O sistema de irrigação por gotejamento foi utilizado o tempo todo, sendo a lâmina de água calculada pelo método do balanço de água no solo, onde são considerados a evaporação de um tanque classe A mais o coeficiente da cultura (Kc) em cada estádio de desenvolvimento (MAROUELLI et al., 1994).

Conduziu-se as plantas em haste única, tutoradas verticalmente com apoio de arames de aço na horizontal.

As características avaliadas foram: área foliar expressa em $\mathrm{cm}^{2}$; comprimento das mudas $(\mathrm{cm})$; massa seca (g) das mudas no momento do transplante; número de folhas total planta $^{-1}$; massa fresca e seca $(\mathrm{g})$ da folhas abaixo da terceira penca e classificação dos frutos em diâmetro (mm) e produção total em $\mathrm{kg}_{\text {planta }} \mathrm{e}^{-1} \mathrm{e} \mathrm{tha}{ }^{-1}$.

\section{RESULTADOS E DISCUSSÃO}

Em relação à área foliar no momento do transplante, o maior resultado foi para estádio de muda no início da frutificação, exceto quando foi utilizado o porta-enxerto 'Anchor T' em que o estádio de plena floração apresentou maiores valores (Tabela 1). Essa diferença era prevista, considerando-se que plantas em estádios diferentes, obrigatoriamente, apresentariam desenvolvimento vegetativo diferenciados. 
Tabela 1 - Comprimento médio e área foliar de plantas no momento do transplante. UNESP/FCA - Botucatu - SP, 1998.

\begin{tabular}{|c|c|c|c|c|}
\hline & & 5 a 6 folhas definitivas & Plena floração & Inicio da frutificação \\
\hline \multirow{4}{*}{ 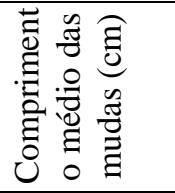 } & 'Kaguemusha' & $22,80 \mathrm{a} \mathrm{C}$ & $46,50 \mathrm{~b} \mathrm{~B}$ & $72,80 \mathrm{a} \mathrm{A}$ \\
\hline & 'Anchor T' & 22,60 a C & $49,50 \mathrm{~b} B$ & $58,50 \mathrm{~b} \mathrm{~A}$ \\
\hline & Pé Franco & $13,80 \mathrm{~b} \mathrm{C}$ & 71,50 a $\mathrm{B}$ & 76,90 a $\mathrm{A}$ \\
\hline & & D.M.S. $(5 \%) 4,21$ & & C.V. (\%) 4,97 \\
\hline \multirow{4}{*}{ 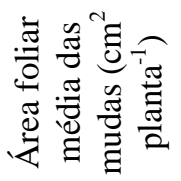 } & 'Kaguemusha' & 103,0 a C & 403,3 с B & $552,6 \mathrm{~b} \mathrm{~A}$ \\
\hline & 'Anchor T' & 52,2 a C & $508,0 \mathrm{~b} \mathrm{~A}$ & $405,4 \mathrm{c} \mathrm{B}$ \\
\hline & Pé Franco & 43,7 a $C$ & 616,4 a B & 790,0 a $\mathrm{A}$ \\
\hline & & D.M.S. (5\%) 64,95 & & C.V.(\%) 9,59 \\
\hline
\end{tabular}

Médias seguidas de mesma letra minúscula na coluna e maiúscula na linha não diferem entre si, pelo teste de Tukey, a $5 \%$ de probabilidade.

Observa-se ainda (Tabela 1) que o pé franco apresenta maior desenvolvimento da área foliar comparado com as mudas enxertadas, pois neste caso houve paralisação temporária do crescimento até que ocorresse a conexão dos vasos e do meristema de cicatrização na região de enxertia, em que diminui a velocidade de translocação da seiva e o vigor da planta nesse período, concordando com a afirmativa de Yoshioka et al. (1981) que observaram que a translocação de ${ }^{14} \mathrm{C}$ do porta-enxerto para o enxerto foi insignificante, atingindo $0,2 \%$ até o $3^{\circ}$ dia após a enxertia e o pegamento do enxerto ocorreu de três a cinco dias após a enxertia.

Ainda observa-se (Tabela 1) que o comprimento das mudas por ocasião do transplante apresentou resultado esperado, sendo que no estádio mais adiantado, início da frutificação, o comprimento das mudas foi maior. Para os porta-enxertos utilizados, o 'Kaguemusha' foi melhor no estádio de início da frutificação, e nos outros estádios de desenvolvimento não houve diferença significativa com o 'Anchor T'.

Quanto à massa seca das mudas (Tabela 2) as mudas enxertadas apresentaram maior massa média seca no estádio de plena floração, e para o pé franco a maior massa média foi alcançado no estádio de início da frutificação, com maior massa média em relação às mudas enxertadas.

Para a avaliação da massa seca, foram descartadas inflorescências e frutos novos utilizando apenas a parte vegetativa. Os porta-enxertos apresentaram desempenho semelhantes em todos os estádios.

Comparando o número total de folhas/planta no final do ciclo nos diferentes estádios de mudas (Tabela 2) verificou-se que o estádio na plena floração do tratamento 'Kaguemusha' conferiu maior número de folhas que o estádio com 5 a 6 folhas definitivas, não sendo diferenciado do início de frutificação, enquanto o 'Anchor
T' em plena floração foi superior a estes dois estádios, e o pé franco não apresentou diferença significativa nos três estádios.

Nota-se (Tabela 3) que, quanto mais adiantado o estádio da muda para transplante, menor foi a massa fresca da folha localizada abaixo do terceiro cacho, sendo esse fato mais evidente para o pé franco, significando que houve, após o estresse inicial gerado pela enxertia, boa recuperação na retomada de crescimento das plantas.

Em todos os estádios não houve diferença entre os porta-enxerto. Para o pé franco ocorreram diferenças mais significativas, ou seja, quanto mais adiantado o estádio de transplante, menor foi a capacidade de recuperação do crescimento em relação às plantas enxertadas.

Estes resultados são concordantes com os obtidos pelo Piróg (1986), em que demonstrou a influência da enxertia de tomateiros com o porta-enxerto KNVF e estes apresentaram maior massa fresca da parte aérea e do sistema radicular.

Os resultados obtidos para massa seca de folha (Tabela 3) não apresentaram diferenças significativas para os diferentes estádios de mudas, exceto para pé franco com cinco a seis folhas definitivas e dentre os portaenxertos, no estádio de plena floração, apenas o 'Anchor $\mathrm{T}$ ' resultou em menor massa seca que pé franco.

$\mathrm{Na}$ análise dos dados de produtividade (Tabela 4) com colheita até o $8^{\text {a }}$ cacho, para os estádios de mudas, observou-se que a melhor produção foi a do tratamento cinco a seis folhas definitivas sem contudo diferir estatisticamente de plena floração que, por sua vez, não diferiu do início de frutificação, concordando com os resultados obtidos por Leskovar \& Cantliffe (1990), Vavrina (1991) e Vavrina \& Orzolek (1993), onde a idade de transplante, não interferiu de maneira significativa na produção do tomateiro (Tabela 4). 
Tabela 2 - Número total de folhas/planta no final do ciclo de produção ( $8^{\text {a }}$ cacho) e massa seca das mudas coletadas no momento do transplante. UNESP/FCA - Botucatu - SP, 1998.

\begin{tabular}{|c|c|c|c|c|}
\hline & & 5 a 6 folhas definitivas & Plena floração & Inicio da Frutificação \\
\hline \multirow{4}{*}{ 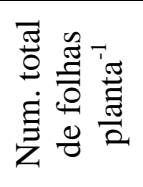 } & 'Kaguemusha' & $34,10 \mathrm{~b} \mathrm{~B}$ & 37,00 a $\mathrm{A}$ & 36,45 a $\mathrm{AB}$ \\
\hline & 'Anchor T' & 34,80 b B & 37,65 a A & 34,00 b B \\
\hline & Pé Franco & 37,50 a A & 36,35 a $\mathrm{A}$ & $36,35 \mathrm{ab} A$ \\
\hline & & D.M.S. $(5 \%) 2,35$ & & C.V. (\%) 3,70 \\
\hline \multirow{4}{*}{ 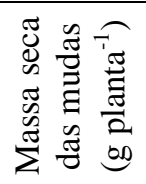 } & 'Kaguemusha' & 0,40 a C & $3,50 \mathrm{~b} \mathrm{~A}$ & $3,30 \mathrm{~b} \mathrm{~B}$ \\
\hline & 'Anchor T' & 0,40 a $C$ & $3,80 \mathrm{~b} \mathrm{~A}$ & $3,10 \mathrm{~b} \mathrm{~B}$ \\
\hline & Pé Franco & 0,20 a $C$ & 5,00 a B & 6,00 a $\mathrm{A}$ \\
\hline & & D.M.S. $(5 \%) 0,27$ & & C.V. (\%) 5,32 \\
\hline
\end{tabular}

Médias seguidas de mesma letra minúscula na coluna e maiúscula na linha não diferem entre si, pelo teste de Tukey, a $5 \%$ de probabilidade.

Tabela 3 - Massa fresca e seca da folha localizada abaixo da terceira penca. UNESP/FCA - Botucatu - SP, 1998.

\begin{tabular}{|c|c|c|c|c|}
\hline & & 5 a 6 folhas definitivas & Plena floração & Inicio da Frutificação \\
\hline \multirow{4}{*}{ 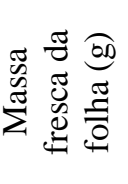 } & 'Kaguemusha' & 284,25 a $A B$ & 307,25 a $\mathrm{A}$ & 218,25 a B \\
\hline & 'Anchor T' & 298,25 a A & $262,75 \mathrm{ab} A B$ & 214,50 a B \\
\hline & Pé Franco & 301,75 a $\mathrm{A}$ & $202,50 \mathrm{~b} \mathrm{~B}$ & $127,00 \mathrm{~b} \mathrm{C}$ \\
\hline & & D.M.S. (5\%) 72,93 & & C.V. (\%) 16,87 \\
\hline \multirow{4}{*}{ 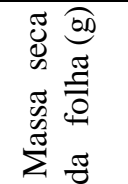 } & 'Kaguemusha' & 12,70 a $\mathrm{A}$ & 12,53 a $\mathrm{AB}$ & 13,29 a $\mathrm{A}$ \\
\hline & 'Anchor T' & 13,05 a $A$ & $11,93 \mathrm{~b} \mathrm{~A}$ & 13,12 a $A$ \\
\hline & Pé Franco & 12,14 a B & 14,14 a $\mathrm{A}$ & 14,92 a A \\
\hline & & D.M.S. (5\%) 1,86 & & C.V. (\%) 8,1 \\
\hline
\end{tabular}

Médias seguidas de mesma letra minúscula na coluna e maiúscula na linha não diferem entre si, pelo teste de Tukey, a 5\% de probabilidade.

Tabela 4 - Produtividade e diâmetro de frutos. UNESP/FCA - Botucatu - SP, 1998.

\begin{tabular}{|c|c|c|c|}
\hline \multirow{2}{*}{ Estádios } & \multicolumn{2}{|c|}{ Produtividade } & \multirow{2}{*}{$\begin{array}{c}\text { Diâmetro médio } \\
(\mathrm{mm})\end{array}$} \\
\hline & $\mathrm{Kg}_{\text {planta }}^{-1}$ & $\mathrm{t} \mathrm{ha}^{-1}$ & \\
\hline 5 a 6 Folhas Definitivas & $4,92 \mathrm{a}$ & 68,33 & $70,48 \mathrm{a}$ \\
\hline Plena Floração & $4,83 \mathrm{ab}$ & 67,08 & $66,67 \mathrm{~b}$ \\
\hline Início da Frutificação & $4,43 \mathrm{~b}$ & 61,52 & $65,31 \mathrm{~b}$ \\
\hline \multicolumn{4}{|l|}{ Porta-Enxertos } \\
\hline 'Kaguemusha' & $4,85 \mathrm{a}$ & 67,36 & $67,09 \mathrm{~b}$ \\
\hline 'Anchor T' & 5,06 a & 70,27 & $69,31 \mathrm{a}$ \\
\hline Pé Franco & $4,27 \mathrm{~b}$ & 59,31 & $66,06 \mathrm{~b}$ \\
\hline D.M.S. (5\%) & 0,43 & & 1,81 \\
\hline C.V. $(\%)$ & 9,15 & & 2,64 \\
\hline
\end{tabular}

Médias seguidas de mesma letra na coluna não diferem entre si, pelo teste de Tukey, a 5\% de probabilidade. 
As plantas enxertadas (Tabela 4), independentes do estádio das mudas, foram semelhantes entre si e apresentaram maior produção que o pé franco. Apesar de ter havido um ganho de produção nas plantas enxertadas, não se atingiu os mesmos níveis relatados por Piróg (1986), que obteve aumento de 30 a $50 \%$ na produção de tomate quando comparada com plantas não enxertadas da mesma cultivar utilizada como enxerto. Vale salientar que pelo fato de o experimento não ter tido maiores dificuldades no que se refere principalmente a ocorrência de patógenos do solo, os porta-enxertos não puderam expressar todo seu potencial produtivo.

Com relação aos diferentes estádios, se houvesse situação de grave infestação de virose na época do transplante, o presente ensaio demonstrou não haver problemas mesmo que atinge o estádio de transplante até a plena floração.

Para o critério de diâmetro dos frutos $(\mathrm{mm})$, a melhor resposta foi quando as mudas foram transplantadas com 5-6 folhas definitivas, enquanto que os outros estádios não apresentaram diferença significativa. O porta-enxerto 'Anchor T' apresentou o melhor desempenho no que refere a diâmetros de frutos (Tabela 4).

Foi realizada observação quanto à precocidade de produção e se constatou que não houve diferença consistente. Isso se deve ao fato de que mesmo havendo diferença em média de dez dias entre as semeaduras das plantas enxertadas e as de pé franco, no campo essa diferença se manteve, iniciando-se as colheitas pelo estádio de inicio de frutificação, seguida de plena floração e por último de cinco a seis folhas definitivas, não apresentando diferença entre os porta-enxertos e o pé franco. Caso houvesse incidência de Tospovírus, o transplante de mudas com mais idade fisiológica não prejudicaria a produção final.

\section{CONCLUSÕES}

A diferença entre os estádios de desenvolvimento mais avançados não apresenta ganhos significativos de produção e qualidade para o tomateiro, sendo que o sistema convencional, onde as mudas foram transplantadas com cinco a seis folhas, é o que apresenta as melhores médias para produção e diâmetro médio de frutos. Para as mudas enxertadas, o porta-enxerto Anchor T apresenta maior produção e diâmetro de frutos.

\section{REFERÊNCIAS BIBLIOGRÁFICAS}

AGRIANUAL. Anuário de agricultura brasileira. São Paulo: FNP Consulta e comércio, 2007. 350 p.
YAMAKAWA, K. Use of rootstocks in solanaceous fuit vegetable production in Japan. JARQ (Jpn. Agric. Res. Q.), Tsukuba, v. 15, n.3, p. 175-179, 1982.

YOSHIOKA, H. Translocation and distribution of photosynthates in tomato plants. JARQ (Jpn. Agric. Res. Q.), Tsukuba, v. 19, n. 4, p. 266-270, 1986.

YOSHIOKA, H.; TAKAHASHI, K,; KOGURE, K. Studies on the translocation and accumulation of photosynthates in young grafted tomato plants. IV. Behavior of photosynthates in young grafted tomato plant. Bull. Veg. Ornamental Crops Res. Stn. Ser. A, Tsushi, v. 8, p. 23-32, 1981.

PIRÓG, J. Effect of grafting methods on KNVF rootsstocks and ilumination on tomato transplant quality. Rocz. Akad. Roln. Poznaniu, Ogrodnictnio, v. 137, n. 10, p. 147-162, 1982.

PIRÓG, J. The influence of seedlling grafting, date of planting and cultivar on tomato yield. Rocz. Akad. Roln. Poznaniu, Ogrodnictnio, v.165, p. 91-106, 1986.

KOGURE, K. Studies on the grafiting of tomatoes. I. Efects of cultural practices in the grafting of KNVF. Hortic. Abstr., Wallingford, v. 49, n. 10, p. 656, 1979 (Abstracts, 7644).

MAROUELLI, W. A. , SILVA, W. L. C., SILVA, H. R. Manejo da irrigação em hortaliças. Brasília: CNPH/ EMBRAPA, 1994. 60p.

LESKOVAR, D.I.; CANTLIFFE, D.J. Does the initial condition of the transplants affect tomato growth and development? Proceedings of the Florida State Horticultural Society. Gainesville, n. 103, p. 148-153, 1990.

VAVRINA, C.S. Effect of transplant age on tomato production. Proceedings of the Flórida State

Horticultural Society, Immokalee, n. 104, p. 225-226, 1991.

VAVRINA, C.S.; ORZOLEK, M.D. Tomato transplant age: Areview. Hort. Technology, Immokalee, v. 3, n.3, p. 313-316, 1993. 